\title{
Pathogenicity of Botryosphaeriaceae Species Isolated from Grapevine Cankers in California
}

\author{
J. R. Úrbez-Torres and W. D. Gubler, Department of Plant Pathology, University of California, Davis 95616, USA
}

\begin{abstract}
Úrbez-Torres, J. R., and Gubler, W. D. 2009. Pathogenicity of Botryosphaeriaceae species isolated from grapevine cankers in California. Plant Dis. 93:584-592.

Fungal species in the family Botryosphaeriaceae have been recently recognized as the most common fungi isolated from grapevine (Vitis vinifera) cankers in California. However, the role of these fungi in causing grapevine dieback as well as their status as canker-causing agents was unknown. Therefore, pathogenicity studies were conducted to determine their importance as grapevine pathogens in California. A total of 72 isolates representing all nine Botryosphaeriaceae species isolated from grapevine cankers from California were used in five different pathogenicity studies. Overall, experiments showed all nine Botryosphaeriaceae species able to infect both young and mature tissues as well as green shoots of the new vegetative growth causing cankers, vascular discoloration, and/or otherwise dark streaking of the wood. However, virulence varied among species. Lasiodiplodia theobromae was the most virulent species followed by Neofusicoccum luteum, N. parvum, and N. australe, all categorized as highly virulent. Botryosphaeria dothidea was considered intermediately virulent and Diplodia mutila, D. seriata, Dothiorella iberica, and D. viticola were shown to be weakly virulent. This study shows species of Botryosphaeriaceae to be much more important pathogens on grapevines than originally thought, and some of them, in view of their virulence, should be considered high risk for causing severe and rapid canker and dieback diseases in the grapevine industry in California.
\end{abstract}

Grapevine (Vitis vinifera L.), currently cultivated on more than 8 million hectares worldwide, is the most widely planted and economically important fruit crop in the world. Grapevine canker diseases, caused by fungal pathogens, are some of the primary factors limiting vineyard longevity and productivity as well as increasing management costs. Fungi associated with canker diseases of grapevine invade primarily through pruning wounds on cordons and spurs of grapevines. However, other mechanical or natural injuries on the plant can be entry points used by these pathogens. Grapevine cankers cause dieback and death of spurs, arms, cordons, and trunks, and eventual vine death. Grapevine cankers are responsible for significant economic losses to the grapevine industry worldwide, and in California alone, the overall loss in net income for wine grapes was estimated to exceed US\$260 million annually (26).

Moller and Kasimatis (17) first described Eutypa lata (Pers.:Fr.) Tul. \& C.

\section{Corresponding author: W. D. Gubler \\ E-mail: wdgubler@ucdavis.edu}

Accepted for publication 20 February 2009.

doi:10.1094/PDIS-93-6-0584

(C) 2009 The American Phytopathological Society
Tul. (syn. Eutypa armeniacae Hansf. \& Carter) as responsible for canker formation and dieback of grapevines in California (17). Since then, E. lata, the causal agent of Eutypa dieback, was considered to be the primary canker-causing pathogen of grapevines in California. However, research conducted in recent years has shown fungal species in the family Botryosphaeriaceae to be associated with different grapevine dieback symptoms including cankers in the main grapegrowing regions of both Northern and Southern Hemispheres $(2,19,28,30,31,34)$. Botryosphaeriaceae species occurring on grapevines are currently placed in the anamorphic genera Fusicoccum, Neofusicoccum, Diplodia, Lasiodiplodia, and Dothiorella $(6,7,20)$.

Symptom expression caused by Botryosphaeriaceae species has been shown to differ from region to region and from different grapevine cultivars (34). As a result, different disease names such as Diplodia cane dieback (8), Macrophoma rot (16), excoriose (18), bot canker $(11,31)$, and black dead arm $(2,9,12)$ have been given in different countries to different types of symptoms often caused by the same fungus. Confusion also has been compounded because disease symptoms caused by these fungi often resemble those caused by other fungal pathogens such as E. lata or Phomopsis viticola (Sacc.) Sacc. $(5,18)$. Addi- tionally, differences in virulence have been reported for the same species within the same and in different grape-growing areas, which has made it difficult to determine the importance of these fungi as grapevine pathogens $(25,28,31,34)$.

Between 2003 and 2006, a survey of California vineyards was conducted to assess the occurrence of fungi associated with grapevine cankers (33). Among other fungi, nine different species in the family Botryosphaeriaceae were isolated from cankers, including Botryosphaeria dothidea, Lasiodiplodia theobromae, Diplodia seriata, D. mutila, Neofusicoccum parvum, N. luteum, N. australe, Dothiorella viticola, and $D$. iberica $(29,33)$. Moreover, isolations from cankers showed Botryosphaeriaceae species to be the main fungi associated with cankers from the major grapevine-growing areas surveyed in California (33). Botryosphaeriaceae species have been recently reported to be the cause of grapevine cankers in South Africa (34), Chile (2,10), Australia $(5,25,28)$, and Mexico (31). However, no data are available regarding the pathogenicity and virulence of Botryosphaeriaceae species in California and thus the role that these fungi play on grapevine health in the state.

The purpose of this study was to evaluate the pathogenicity and virulence of Botryosphaeriaceae species isolated from grapevine cankers and therefore determine which species pose the greatest threat to grapevines in California.

\section{MATERIALS AND METHODS}

Fungal isolates. Seventy-two fungal isolates, representing the nine different Botryosphaeriaceae species isolated from grapevine cankers from different geographical regions in California, were selected to conduct the pathogenicity studies (Table 1). Identity of the different Botryosphaeriaceae species was determined based on previous morphological studies and analyses of nucleotide sequences of three genes (29,33). All isolates were maintained in our collection in $4 \%$ potato dextrose agar (PDA) (Difco Laboratories, Detroit, MI) mycelial plugs in glass tubes with sterile distilled water at $5^{\circ} \mathrm{C}$ until use. In addition, representative Botryosphaeriaceae sequences and isolates from California were deposited in GenBank and in 
Table 1. Mean lesion length caused by Botryosphaeriaceae species from California on rooted-potted Crimson dormant cuttings in the greenhouse

\begin{tabular}{|c|c|c|c|c|c|c|}
\hline Species & Isolate & Origin & $\mathbf{A T C C}^{\mathbf{a}}$ & GenBank ITS & $\begin{array}{l}\text { Mean lesion length } \\
\quad(\mathrm{mm})^{\mathrm{b}} \pm \mathrm{SE}\end{array}$ & Reisolation $^{c}$ \\
\hline Lasiodiplodia theobromae & UCD196Co & Riverside County & MYA-3687 & DQ233592 & $315.3 \pm 2.7 * \mathrm{~d}$ & 3 \\
\hline L. theobromae & UCD1962SB & Santa Barbara Co. & - & DQ233597 & $290 \pm 2.2 *$ & 3 \\
\hline L. theobromae & UCD526Kr & Kern Co. & - & DQ233595 & $282.6 \pm 6 *$ & 3 \\
\hline L. theobromae & UCD205Co & Riverside Co. & MYA-3689 & DQ008310 & $264.1 \pm 1.1 *$ & 3 \\
\hline L. theobromae & UCD220Co & Riverside Co. & MYA-3691 & DQ008312 & $245.4 \pm 8.6 *$ & 3 \\
\hline L. theobromae & UCD206Co & Riverside Co. & MYA-3690 & DQ008311 & $207.3 \pm 6.6 *$ & 3 \\
\hline L. theobromae & $\mathrm{UCD} 256 \mathrm{Ma}$ & Madera Co. & - & DQ233594 & $184.5 \pm 5.1 *$ & 3 \\
\hline L. theobromae & UCD1814Md & Madera Co. & - & DQ233596 & $177.3 \pm 5 \quad *$ & 3 \\
\hline Diplodia seriata & UCD244Ma & Madera Co. & MYA-3692 & DQ008314 & $148 \pm 6 *$ & 2 \\
\hline D. seriata & UCD465Fr & Fresno Co. & - & DQ008316 & $128.6 \pm 5.5 *$ & 2 \\
\hline D. seriata & UCD352Mo & Monterey Co. & MYA-3693 & DQ008315 & $112.3 \pm 5.9 *$ & 3 \\
\hline D. seriata & UCD602Kr & Kern Co. & MYA-3694 & DQ008317 & $93.3 \pm 2.2 *$ & 3 \\
\hline D. seriata & UCD645So & Sonoma Co. & - & DQ008319 & $61 \pm 3.1$ & 2 \\
\hline D. seriata & UCD614Tu & Tulare Co. & - & DQ008318 & $59.1 \pm 2.8$ & 1 \\
\hline D. seriata & UCD710SJ & San Joaquin Co. & MYA-3695 & DQ008321 & $28 \pm 9.1$ & 1 \\
\hline D. seriata & UCD666Na & Napa Co. & - & DQ008320 & $17.3 \pm 2.3$ & 1 \\
\hline Diplodia mutila & UCD288Ma & Madera Co. & - & DQ008313 & $128.7 \pm 5.9 *$ & 3 \\
\hline D. mutila & UCD1965SB & Santa Barbara Co. & MYA-3697 & DQ233599 & $125.5 \pm 4.5 *$ & 1 \\
\hline D. mutila & UCD1953SB & Santa Barbara Co. & MYA-3696 & DQ233598 & $122 \pm 8.6 *$ & 3 \\
\hline D. mutila & UCD1951SB & Santa Barbara Co. & - & - & $95.3 \pm 1.4 *$ & 1 \\
\hline D. mutila & UCD1955SB & Santa Barbara Co. & - & - & $85 \pm 4.4 *$ & 1 \\
\hline D. mutila & UCD300Ma & Madera Co. & - & - & $84.1 \pm 6.4 *$ & 3 \\
\hline D. mutila & UCD289Ma & Madera Co. & - & - & $67.6 \pm 5.1 *$ & 2 \\
\hline D. mutila & UCD1966SB & Santa Barbara Co. & - & - & $61.6 \pm 3.7$ & 3 \\
\hline Neofusicoccum australe & UCD1313So & Sonoma Co. & - & - & $319 \pm 7.2 *$ & 2 \\
\hline N. australe & UCD1467So & Sonoma Co. & MYA-3699 & DQ233610 & $273 \pm 8.2 *$ & 3 \\
\hline N. australe & UCD1498So & Sonoma Co. & - & - & $248.5 \pm 5.2 *$ & 3 \\
\hline N. australe & UCD1469So & Sonoma Co. & - & - & $226.2 \pm 9.3 *$ & 3 \\
\hline N. australe & UCD1468So & Sonoma Co. & - & - & $215.3 \pm 8.9 *$ & 3 \\
\hline N. australe & UCD1490So & Sonoma Co. & - & - & $188.6 \pm 12.6 *$ & 3 \\
\hline N. australe & UCD1314So & Sonoma Co. & MYA-3698 & DQ008323 & $177.6 \pm 8.1 *$ & 3 \\
\hline N. australe & UCD1315So & Sonoma Co. & - & - & $139.7 \pm 7.8 *$ & 3 \\
\hline Neofusicoccum luteum & UCD2070Te & Riverside Co. & - & - & $313.6 \pm 6.8 *$ & 3 \\
\hline N. luteum & UCD2103Te & Riverside Co. & MYA-3703 & DQ233608 & $289.7 \pm 7.1 *$ & 3 \\
\hline N. luteum & UCD2089Te & Riverside Co. & - & DQ233605 & $281 \pm 6.3 *$ & 3 \\
\hline N. luteum & UCD2057Te & Riverside Co. & MYA-3700 & DQ233625 & $216.3 \pm 8.9 *$ & 3 \\
\hline N. luteum & UCD2118Te & Riverside Co. & MYA-3704 & DQ233609 & $208 \pm 5.6 *$ & 3 \\
\hline N. luteum & UCD2090Te & Riverside Co. & MYA-3701 & DQ233606 & $205.6 \pm 6.8 *$ & 3 \\
\hline N. luteum & UCD2069Te & Riverside Co. & - & - & $205.3 \pm 8.5 *$ & 3 \\
\hline N. luteum & UCD2098Te & Riverside Co. & MYA-3702 & DQ233607 & $73.1 \pm 2.2 *$ & 3 \\
\hline Neofusicoccum parvum & UCD646So & Sonoma Co. & MYA-3706 & DQ008329 & $335.7 \pm 4.9 *$ & 3 \\
\hline N. parvum & UCD759St & Stanislaus Co. & - & DQ233611 & $310.2 \pm 4 \quad *$ & 3 \\
\hline N. parvum & UCD642So & Sonoma Co. & MYA-3705 & DQ008328 & $278.3 \pm 4.8 *$ & 3 \\
\hline N. parvum & UCD1844Me & Mendocino Co. & - & - & $268 \pm 1.1 *$ & 3 \\
\hline N. parvum & UCD650So & Sonoma Co. & - & - & $253.3 \pm 7.1 *$ & 3 \\
\hline N. parvum & UCD649So & Sonoma Co. & - & - & $238.4 \pm 2.1 *$ & 3 \\
\hline N. parvum & UCD1349So & Sonoma Co. & - & DQ008330 & $195.3 \pm 1.6 *$ & 3 \\
\hline N. parvum & UCD $1125 \mathrm{Na}$ & Napa Co. & - & DQ233612 & $178 \pm 4.5 *$ & 3 \\
\hline Botryosphaeria dothidea & UCD $1181 \mathrm{Me}$ & Mendocino Co. & MYA-3709 & DQ008325 & $277.8 \pm 8.4 *$ & 2 \\
\hline B. dothidea & UCD1672Yo & Yolo Co. & MYA-3710 & DQ233603 & $158.6 \pm 9.8 *$ & 1 \\
\hline B. dothidea & UCD1065So & Sonoma Co. & MYA-3707 & DQ233601 & $136.7 \pm 6.3 *$ & 2 \\
\hline B. dothidea & UCD $1156 \mathrm{Me}$ & Mendocino Co. & - & DQ233602 & $134.3 \pm 4.6 *$ & 2 \\
\hline B. dothidea & UCD1213Me & Mendocino Co. & - & DQ008326 & $118.3 \pm 4.3 *$ & 2 \\
\hline B. dothidea & UCD1064So & Sonoma Co. & - & DQ233600 & $108.5 \pm 4.3 *$ & 3 \\
\hline B. dothidea & UCD1333So & Sonoma Co. & - & DQ008327 & $94.5 \pm 6.8 *$ & 3 \\
\hline B. dothidea & UCD1066So & Sonoma Co. & MYA-3708 & DQ008324 & $86 \pm 3.2 *$ & 3 \\
\hline Dothiorella viticola & UCD2100Te & Riverside Co. & - & - & $103 \pm 8.5 *$ & 2 \\
\hline D. viticola & UCD1962SB & Santa Barbara Co. & - & - & $79.1 \pm 2.2 *$ & 3 \\
\hline D. viticola & UCD1435SLO & San Luis Obispo Co. & MYA-4112 & EF202007 & $63.6 \pm 5.1$ & 2 \\
\hline D. viticola & UCD1958SB & Santa Barbara Co. & MYA-4114 & EF202011 & $61.3 \pm 7.7$ & 1 \\
\hline D. viticola & UCD2073Te & Riverside Co. & MYA-4115 & EF202012 & $51.6 \pm 2.5$ & 1 \\
\hline D. viticola & UCD1642Yo & Yolo Co. & MYA-4113 & EF202010 & $46 \pm 9.1$ & 1 \\
\hline D. viticola & UCD1360So & Sonoma Co. & - & - & $34.3 \pm 1$ & 1 \\
\hline D. viticola & UCD3So & Sonoma Co. & MYA-4116 & EF202013 & $30 \pm 6.1$ & 1 \\
\hline Dothiorella iberica & UCD1396SLO & San Luis Obispo Co. & - & - & $81.3 \pm 5.1 *$ & 2 \\
\hline D. iberica & UCD1413SLO & San Luis Obispo Co. & - & - & $43.6 \pm 3.3$ & 2 \\
\hline D. iberica & UCD1439SLO & San Luis Obispo Co. & MYA-4110 & EF202008 & $35 \pm 1.6$ & 1 \\
\hline D. iberica & UCD1410SLO & San Luis Obispo Co. & - & - & $34.8 \pm 1.8$ & 2 \\
\hline D. iberica & UCD1381SLO & San Luis Obispo Co. & - & - & $24.5 \pm 1.1$ & 1 \\
\hline D. iberica & UCD1388SLO & San Luis Obispo Co. & - & - & $22.1 \pm 7.8$ & 2 \\
\hline D. iberica & UCD1399SLO & San Luis Obispo Co. & - & - & $19 \pm 0.6$ & 3 \\
\hline D. iberica & UCD1448SLO & San Luis Obispo Co. & MYA-4111 & EF202008 & $16.6 \pm 0.3$ & 3 \\
\hline Control & Control & - & - & - & $14.7 \pm 0.3$ & 0 \\
\hline
\end{tabular}

a ATCC, American Type Culture Collection. ITS, internal transcribe spacer accession numbers from sequences deposited in the GenBank.

${ }^{\mathrm{b}}$ Mean values correspond to the sum of both upward and downward extent of vascular discoloration measured from the point of inoculation.

c Number of samples from which the fungus was reisolated out of 3 samples inoculated.

$\mathrm{d} *$, Significantly different than the uninoculated controls at the 0.05 level. 
the American Type Culture Collection (ATCC), respectively (Table 1).

Inoculum preparation. Pathogenicity studies were conducted using either fungal mycelium or a conidial suspension. Fungal mycelium of each isolate was recovered from our collection after plating of a mycelial plug on PDA and incubating it at room temperature $\left(23 \pm 2^{\circ} \mathrm{C}\right)$ for 10 days. Spore suspensions were prepared as follows: 7- to 10-day-old mycelial plugs for each of the isolates used were placed onto petri plates containing $2 \%$ water agar (Difco) and autoclaved pine needles. Plates were incubated at $25^{\circ} \mathrm{C}$ under intermittent $(12 \mathrm{~h})$ cycle fluorescent light until pycnidia and sporulation were observed. Mature pycnidia of each Botryosphaeriaceae anamorph were collected and separately placed in $1.5-\mathrm{ml}$ sterile microcentrifuge tubes. Pycnidia were gently crushed in sterile distilled water using a sterile plastic pestle. Water containing the conidia was filtered through four layers of cheesecloth in order to remove both mycelial and pycnidia fragments. Spore suspensions were adjusted to a final density of approximately $1 \times 10^{5}$ conidia/ml using a hemacytometer.

Pathogenicity studies. Five different pathogenicity tests were conducted.

Greenhouse-potted grapevine inoculations. Eight different isolates of each of the nine Botryosphaeriaceae species were used in this experiment (Table 1). The experiment was conducted using 1-yearold dormant grapevine cuttings of $\mathrm{cv}$. Crimson. Dormant cuttings were cut to a uniform length of five internodes $(50 \mathrm{~cm})$, rooted, and planted in May 2007 as described by Úrbez-Torres et al. (31). Inoculations were made by wounding the tissue between the fourth and fifth internode using a 5-mm-diameter cork borer and placing a 5-mm-diameter mycelial plug from a 7-day-old culture into the wound. Then, wounds were sealed with petroleum jelly and wrapped with Parafilm (Pechiney, Chicago, IL). Noncolonized agar plugs were used for the negative control. After inoculation, potted vines were placed in a greenhouse. Three cuttings per fungal isolate or control treatment were used, and plants were arranged in a completely randomized design on the greenhouse bench. Plants were maintained under controlled temperature $\left(30 \pm 2^{\circ} \mathrm{C}\right)$ and relative humidity (40\%) and watered as needed. Six months after inoculation, cuttings were surface disinfected in $10 \%$ sodium hypochlorite for $5 \mathrm{~min}$. After air-drying, canes were sectioned longitudinally in half through the point of inoculation, and the extent of vascular discoloration was measured both upward and downward from the point of inoculation (Fig. 1d). In order to fulfill Koch's postulates, small pieces of necrotic tissue from the edge of each lesion were cut and placed on PDA amended with tetracycline hydrochloride (PDA-tet,
$0.01 \%$ ) (Sigma-Aldrich, St. Louis, MO) to recover the inoculated fungus.

Spur inoculations. Three different isolates of each of the nine Botryosphaeriaceae species collected from California vineyards were used in this experiment (Table 2). The field trial was conducted in a 14-year-old Syrah vineyard located at the University of California, Kearny Agricultural Center in Parlier. Vines were cordon trained and spur pruned. Grapevines were prepruned 8 to 10 buds in January 2006. Fresh pruning wounds were inoculated immediately by applying $50 \mu \mathrm{l}$ of a $1 \times 10^{5}$ conidia/ml suspension from each isolate prepared as previously described. Control treatments were inoculated by applying 50 $\mu \mathrm{l}$ of sterile distilled water. One 1-year-old cane per grapevine on each of 10 grapevines per fungal treatment or control was inoculated, and treatments were applied in a completely randomized design. Canes were collected 13 months after inoculation and brought to the laboratory where surface disinfection was conducted as previously described. Canes were sectioned longitudinally in half and the extent of vascular discoloration was measured from the point of infection. Koch's postulates were fulfilled by isolation from infected tissue.

Inoculation of green shoots. Three different isolates of each of the nine Botryosphaeriaceae species were used in this study (Table 3 ). The field trial was conducted in a 7-year-old Red Globe vineyard at the University of California Field Station in Davis. The experimental design and number of replicates were the same as in the spur inoculation pathogenicity test. Green shoots of the new vegetative growth were inoculated with mycelial plugs by wounding between the fourth and fifth internodes in June 2007 as described in the greenhouse-potted grapevine pathogenicity test. Shoots were collected 5 months after inoculation and brought to the laboratory. Shoots were then disinfected, sectioned longitudinally in half through the point of inoculation, upward and downward vascular discoloration was recorded from the inoculation point, and fungal reisolation was conducted as described above.

Cordon inoculations. One isolate of each of the nine Botryosphaeriaceae species was used in this experiment (Table 4). Field trials were conducted in different grapevines of the same Syrah and Red Globe vineyards previously described. Inoculations were made on mature tissue at the end of the cordon between the last two spur positions by drilling a hole 10 to 15 $\mathrm{mm}$ deep using a 5-mm-diameter electric drill. Cordons were immediately inoculated by placing a mycelial plug in the hole. Wounds were sealed and wrapped as previously described. Ten cordons per fungal isolate were inoculated in each Syrah and Red Globe vineyard in January and February of 2006, respectively. Fungal treatments also included one isolate of $E$. lata (Table 4), as well as noncolonized agar plugs for a negative control. Cordons were collected 24 months after inoculation. Cordons were disinfected, sectioned longitudinally in half through the point of inoculation as shown in Figure $1 \mathrm{~h}$, and vascular discoloration recorded both upward and downward from the point of inoculation. Fungal reisolations were made as previously described.

Lath-house rooted grapevine inoculations. One isolate of each of the nine Botryosphaeriaceae species was used in this experiment (Table 5). Two-year-old rooted Thompson Seedless grapevines were individually planted in 3.8-liter pots containing sterile Yolo fine sandy loam soil. Plants were placed in a lath-house under ambient environmental conditions and watered as needed at the University of California Experimental Station in Davis in April 2006. After 2 months, the midpart of the trunk of each grapevine was wounded and inoculated using mycelium plugs as previously described. Noncolonized agar plugs were used for negative control. Ten plants per isolate or control were inoculated in a completely randomized design. Plants were collected 12 months after inoculation, sectioned longitudinally in half through the point of inoculation, and extent of upward and downward vascular discoloration was measured. Koch's postulates were fulfilled as previously described.

Data analyses. Data from the different assays were analyzed using SAS (Version 9.1.3; SAS Institute, Cary, NC). Homogeneity of variance was tested using Levene's test. Residuals were visually inspected for each experiment, and when necessary the $\log _{10}$ transformation was used to improve homogeneity of variance. Within each of the five assays, difference in length of discoloration caused by each Botryosphaeriaceae isolate was determined by oneway analyses of variance. Treatment means were compared using Fisher's least significant difference (LSD) test at the 5\% significance level. A two-way ANOVA was performed to determine significant differences between Syrah and Red Globe grape cultivars in the cordon pathogenicity test. Additionally, virulence of Botryosphaeriaceae species across all pathogenicity assays was evaluated. Due to the heterogeneity of the different experimental designs (incubation time, inoculum used, and age of tissue inoculated), a ranking approach was used. The final virulence rank for each Botryosphaeriaceae species was determined by averaging the rank of each species across all six pathogenicity experiments (Syrah and Red Globe cordon inoculations were treated as separate trials). Species rank within each trial was determined by ranking all isolates from most virulent (rank 10) to least virulent (rank 2) including control (rank 1) depending on the discoloration they caused. Species virulence ranks obtained across all six 


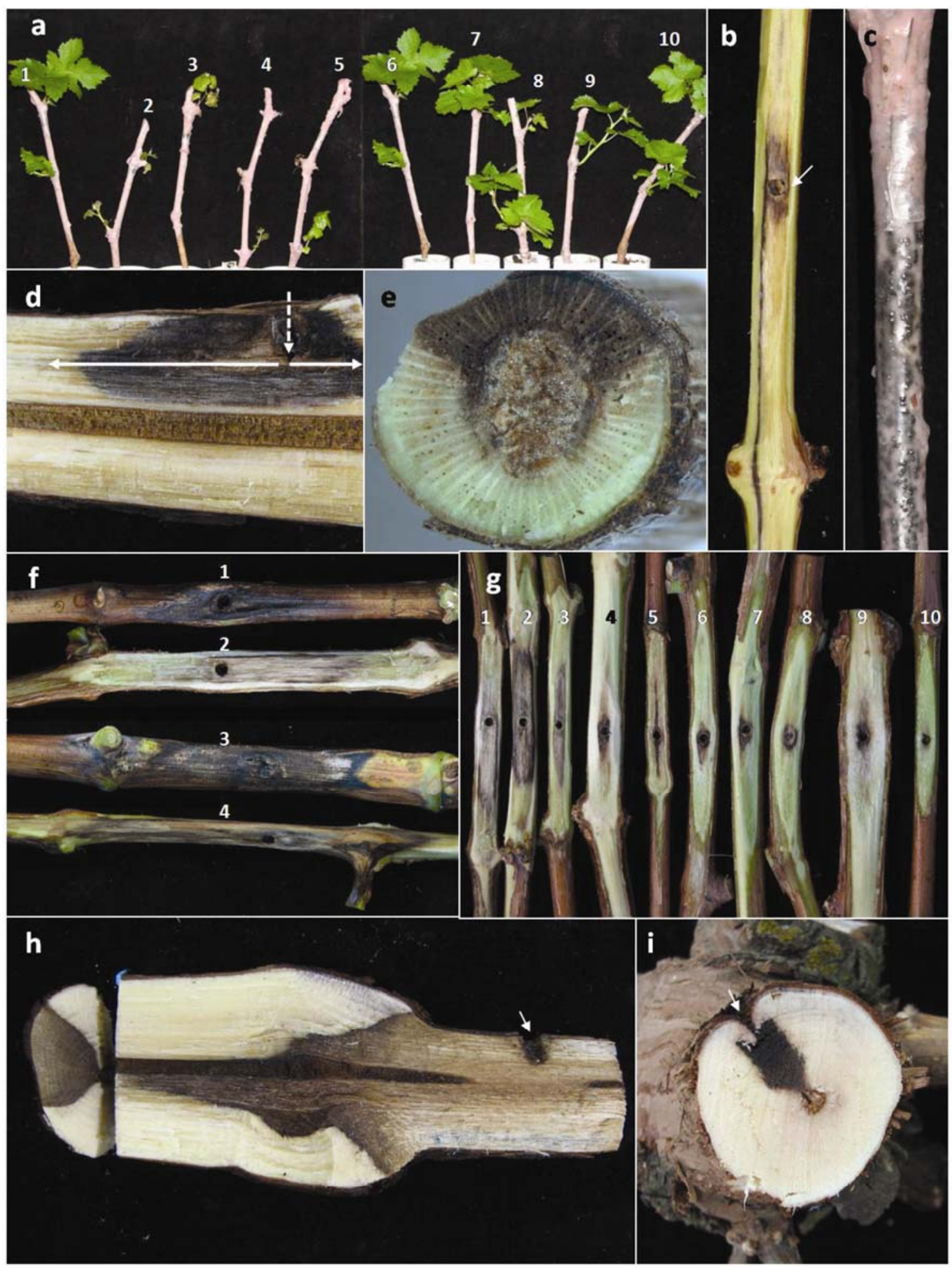

Fig. 1. Symptoms caused by Botryosphaeriaceae species on inoculated grapevines. a, Greenhouse-potted dormant Crimson cuttings 6 weeks after inoculation. Cuttings inoculated with highly virulent species $(2=$ UCD196Co, $3=$ UCD646So, $4=2103$ Te, $5=$ UCD1314So $)$ showed poor or no new growth in comparison with the normal growth of cuttings inoculated with weakly pathogenic species $(1=$ control, $6=$ control, $7=\mathrm{UCD} 465 \mathrm{Fr}, 8=$ UCD1065So, 9 = UCD3So, $10=$ UCD14395Lo). b, Dark wood streaking caused by Neofusicoccum parvum (UCD646So). White arrow shows point of inoculation. c, Pycnidia of Lasiodiplodia theobromae (UCD220Co) formed under wax on Crimson cuttings 6 weeks after inoculation. d, Longitudinal section through point of inoculation (dash arrow) showing downward and upward vascular discoloration (white arrows) in a Crimson cutting. e, Cross section showing a characteristic wedge-shaped canker. f, Lesions caused by Botryosphaeriaceae species on Red Globe green tissue 5 months after inoculation $(1=\mathrm{UCD} 220 \mathrm{Co}, 2=\mathrm{UCD} 220 \mathrm{Co}, 3=\mathrm{UCD} 1314 \mathrm{So}, 4=\mathrm{UCD} 1314$ So $)$. Lignified canes showed necrotic areas around point of inoculation and flat canker surface. g, Vascular discoloration caused by Botryosphaeriaceae species on Red Globe green tissue 5 months after inoculation $(1=$ UCD220Co, 2 = UCD1498So, $3=$ UCD2118Te, 4 = UCD642So, $5=$ UCD1333Na, $6=$ UCD352Mo, $7=$ UCD1965SB, $8=$ UCD1439SLO, $9=$ UCD2073Te, $10=$ control). h, Cross and longitudinal section showing a wedge-shaped canker caused by L. theobromae (UCD205Co) on cv. Syrah mature tissue (cordon). i, Wedge-shaped canker caused by $N$. parvum (UCD642So) on Red Globe mature tissue (cordon). Arrows indicate points of inoculation. 
trials were analyzed using a KruskalWallis test (nonparametric one-way ANOVA) where total sample size $(N)=60$, treatments $(k)=10$, nine spp. + control, and replicates $(n)=6$.

\section{RESULTS}

Greenhouse-potted grapevine inoculations. Mean lengths of vascular discoloration caused by the 72 Botryosphaeriaceae isolates tested and the controls are shown in Table 1. Five to six weeks after inoculation, plants inoculated with $L$. theobromae, $N$. parvum, $N$. australe, and $N$. luteum isolates showed poor bud development and stunted green shoot growth (Fig. 1a). Plants inoculated with $B$. dothidea, $D$. seriata, D. mutila, D. iberica, and D. viticola showed normal green shoot development and did not differ from controls (Fig. 1a). Six months after inoculation, dark, rotting lesions and/or streaking of the wood developing both upward and downward from the point of inoculation were observed in all inoculated plants (Fig. 1b). Pycnidia on the surface of the bark of all 9 Botryosphaeriaceae species were commonly observed several weeks after inoculation (Fig. 1c). Wedge-shaped cankers were observed in cane cross sections of all plants inoculated with $L$. theobromae, $N$. parvum, N. australe, and N. luteum (Fig. 1e), and lesions often reached the bottom of the canes (root area). Fifty-five of 72 Botryosphaeriaceae isolates produced significantly longer lesions compared to the control (14.7 mm) (Table 1). However, lesion lengths varied among species and within isolates of the same species. All $L$. theobromae, N. parvum, N. luteum, N. australe, and B. dothidea isolates tested in this experiment were highly virulent (Table 1). Vascular discoloration of at least one isolate of D. seriata, D. mutila, D. viticola, and $D$. iberica was significantly longer than that of the control (Table 1). N. parvum (UCD646So), $N$. australe (UCD1313So), L. theobromae (UCD196Co), and N. luteum (UCD2070Te) isolates were the most virulent on Crimson potted grapevines, and produced lesions over $300 \mathrm{~mm}$ in length (Table 1). On the other hand, although D. seriata (UCD710St), D. viticola (UCD3So), and most of the D. iberica isolates were reisolated from the observed cankers, the extent of vascular discoloration they produced was smaller than 30 $\mathrm{mm}$ in length and not significantly different from the noninoculated controls (Table 1). N. luteum isolates showed the highest variability in virulence within species, causing vascular discoloration ranging from 73.1 to $313.6 \mathrm{~mm}$. No fungi were reisolated from the slightly discolored tissue of the controls.

Spur inoculations. Mean lengths of vascular discoloration caused by 27 Botryosphaeriaceae isolates and the controls are shown in Table 2. Thirteen months after inoculation, canes had developed dark, rotting lesions and/or dark wood streaking originating downward from the point of inoculation. V-shaped cankers were observed when cross sections were

Table 2. Mean lesion length caused by Botryosphaeriaceae species from California on Syrah spurs

\begin{tabular}{|c|c|c|c|}
\hline Isolate & Species & $\begin{array}{l}\text { Mean lesion length } \\
\quad(\mathrm{mm}) \pm \mathrm{SE}^{\mathrm{a}}\end{array}$ & Reisolation $^{\mathrm{b}}$ \\
\hline UCD646So & Neofusicoccum parvum & $125.7 \pm 16.8 \mathrm{a}$ & 10 \\
\hline UCD205Co & Lasiodiplodia theobromae & $123.9 \pm 16.5 \mathrm{a}$ & 8 \\
\hline UCD1125Na & N. parvum & $105.7 \pm 11.2 \mathrm{abc}$ & 10 \\
\hline UCD642So & N. parvum & $105.6 \pm 19.6 \mathrm{abcd}$ & 10 \\
\hline UCD256Ma & L. theobromae & $104.7 \pm 15.9 \mathrm{abcd}$ & 10 \\
\hline UCD1814Md & L. theobromae & $92.5 \pm 14.9 \mathrm{abcd}$ & 10 \\
\hline UCD2118Te & Neofusicoccum luteum & $88.7 \pm 19.3$ bcde & 10 \\
\hline UCD2103Te & $N$. luteum & $80.2 \pm 15.8$ bcde & 10 \\
\hline UCD2098Te & N. luteum & $70.6 \pm 9.4$ bcdef & 9 \\
\hline UCD1467So & Neofusicoccum australe & $70.5 \pm 11.3 \mathrm{cdef}$ & 10 \\
\hline UCD1065So & Botryosphaeria dothidea & $58.8 \pm 14.8$ efgh & 10 \\
\hline UCD288Ma & Diplodia mutila & $50.5 \pm 9.8$ efghi & 8 \\
\hline UCD710SJ & Diplodia seriata & $49.1 \pm 13.6$ efghi & 10 \\
\hline UCD1410SLO & Dothiorella iberica & $46.4 \pm 9.3$ efghi & 9 \\
\hline UCD1066So & B. dothidea & $45.9 \pm 6.6$ efghi & 7 \\
\hline UCD1469So & N. australe & $44.8 \pm 10.4$ fghi & 10 \\
\hline UCD1965SB & D. mutila & $42.2 \pm 8$ ghi & 10 \\
\hline UCD2073Te & Dothiorella viticola & $41.5 \pm 7.5 \mathrm{hi}$ & 10 \\
\hline UCD1435SLO & D. viticola & $38.9 \pm 12.2 \mathrm{hi}$ & 8 \\
\hline UCD1439SLO & D. iberica & $38.8 \pm 6.3 \mathrm{hi}$ & 9 \\
\hline UCD1953SB & D. mutila & $38.7 \pm 5.8 \mathrm{hi}$ & 7 \\
\hline UCD1181Me & B. dothidea & $38.4 \pm 8.1 \mathrm{hi}$ & 10 \\
\hline UCD352Mo & D. seriata & $38.1 \pm 7.7 \mathrm{hi}$ & 8 \\
\hline UCD1314So & N. australe & $36.8 \pm 8.4 \mathrm{hi}$ & 7 \\
\hline UCD1448SLO & D. iberica & $34.4 \pm 5.3 \mathrm{i}$ & 6 \\
\hline UCD1642Yo & D. viticola & $33.6 \pm 4.9 \mathrm{i}$ & 7 \\
\hline UCD244Ma & D. seriata & $32.3 \pm 7.2 \mathrm{i}$ & 10 \\
\hline Control & Control & $13.4 \pm 1.2 \mathrm{j}$ & 0 \\
\hline
\end{tabular}

${ }^{a}$ Means with the same letter are not significantly different at the 0.05 level. Mean values correspond to the extent of vascular discoloration measured downward from the point of inoculation.

${ }^{b}$ Number of samples from which the fungus was reisolated out of 10 samples inoculated. made on symptomatic canes (Fig. 1e). All 27 Botryosphaeriaceae isolates tested were considered pathogenic in 1-year-old Syrah canes, and produced significantly longer lesions compared to the control $(13.4 \mathrm{~mm})$ (Table 2). However, lesion lengths varied among species and within isolates of the same species. N. parvum, L. theobromae, and $N$. luteum isolates caused significantly longer lesion means (112.3, 107.1, and $79.8 \mathrm{~mm}$, respectively) than the rest of Botryosphaeriaceae species and were considered the most virulent species on Syrah spurs (Table 2). D. seriata, D. iberica, and D. viticola isolates caused the smallest lesion means $(39.9,39.8$, and $38 \mathrm{~mm}$, respectively) and were considered the least virulent species on Syrah canes. N. parvum isolate UCD646So and $L$. theobromae isolate UCD205Co caused the largest lesions (125.7 and $123.9 \mathrm{~mm}$, respectively), and $D$. iberica isolate UCD1448SLO, $D$. viticola isolate UCD1642Yo, and D. seriata isolate UCD244Ma caused the smallest lesions $(34.4,33.6$, and $32.3 \mathrm{~mm}$, respectively) among all isolates tested (Table 2). $N$. australe isolates UCD1467So and UCD1314So showed the highest variability in virulence within species, and their vascular discoloration varied from 36.8 to $70.5 \mathrm{~mm}$, respectively. Reisolation of any specific isolate, shown in Table 2, was always higher than $60 \%$. No Botryosphaeriaceae fungi were reisolated from the slightly discolored tissue from the controls.

Inoculation of green shoots. Mean lengths of vascular discoloration caused by the 27 Botryosphaeriaceae isolates tested and the controls are shown in Table 3. Five months after inoculation, lignified canes showed dark flat lesions originating downward and upward from the point of inoculation (Fig. 1f and g). Twenty-one out of 27 Botryosphaeriaceae isolates produced significantly longer lesions in green Red Globe shoots compared to the control (3.3 mm) (Table 3). However, lesion lengths varied among species and within isolates of the same species. L. theobromae and $N$. australe isolates caused significantly longer lesion means (37.4 and 28.7 $\mathrm{mm}$, respectively) than the rest of Botryosphaeriaceae species and were considered the most virulent species on green shoots of cv. Red Globe (Table 3). D. mutila, D. iberica, and $D$. viticola isolates caused the smallest lesions $(11.3,9.5$, and $8.5 \mathrm{~mm}$, respectively) and were considered the least virulent species. $L$. theobromae isolate UCD220Co caused the largest lesions (45.2 $\mathrm{mm}$ ) among all Botryosphaeriaceae isolates (Table 3 ). D. viticola isolates UCD1435SLO and UCD1642Yo, and D. iberica isolate UCD1448SLO caused the smallest lesions among all isolates tested (7.2, 6.6, and $6.3 \mathrm{~mm}$, respectively) (Table 3 ) and were not significantly different from the control. Reisolation of any specific isolate, shown in Table 3, was always higher than $60 \%$, with the exception of 
isolates UCD1435SLO and UCD1448SLO, which showed only $40 \%$ reisolation. No Botryosphaeriaceae fungi were reisolated from the slightly discolored tissue from the controls.

Cordon inoculation. Mean extent of vascular discoloration caused by the nine Botryosphaeriaceae isolates tested, E. lata, four months after inoculation, V-shaped canker lesions were the most common symptom observed in the inoculated mature tissue (Fig. 1h and i). Dark wood streaking extending beyond the canker lesion was also observed in cordons inocuand controls are shown in Table 4. Twenty-

lated with L. theobromae (UCD1814Md), $N$. australe (UCD1324So), N. parvum (UCD642So), N. luteum (UCD2118Te), and $B$. dothidea (UCD1181Me). Based on length of vascular discoloration and canker formation, the nine Botryosphaeriaceae isolates tested in this trial were considered highly virulent, intermediately virulent, or weakly virulent in both cultivars when compared to the control (Table 4). A twoway ANOVA showed no significant differences in the extent of vascular discoloration between the same Botryosphaeriaceae species regardless of cultivar $(F=0.34, P$ $=0.9683)$. L. theobromae, $N$. australe, $N$.

Table 3. Mean lesion length caused by Botryosphaeriaceae species on attached green shoots of $\mathrm{cv}$. Red Globe

\begin{tabular}{|c|c|c|c|}
\hline Isolate & Species & $\begin{array}{l}\text { Mean lesion length } \\
(\mathrm{mm}) \pm \mathrm{SE}^{\mathrm{a}}\end{array}$ & Reisolation $^{b}$ \\
\hline UCD220Co & Lasiodiplodia theobromae & $42.5 \pm 7.6 \mathrm{a}$ & 10 \\
\hline $\mathrm{UCD} 256 \mathrm{Kr}$ & L. theobromae & $41.6 \pm 8.8 \mathrm{ab}$ & 10 \\
\hline UCD1498So & Neofusicoccum australe & $36.2 \pm 11.3 \mathrm{abc}$ & 9 \\
\hline UCD1467So & N. australe & $30.5 \pm 12.7 \mathrm{bcd}$ & 10 \\
\hline UCD205Co & L. theobromae & $25.5 \pm 3.4 \mathrm{cde}$ & 10 \\
\hline UCD2118Te & Neofusicoccum luteum & $24.2 \pm 5.1$ cdef & 10 \\
\hline UCD $1333 \mathrm{Na}$ & Botryosphaeria dothidea & $23 \pm 6.3 \mathrm{cdefg}$ & 8 \\
\hline UCD352Mo & Diplodia seriata & $21.8 \pm 6.1 \mathrm{defg}$ & 10 \\
\hline UCD710SJ & D. seriata & $20.6 \pm 3.6$ defgh & 10 \\
\hline UCD1314So & N. australe & $19.6 \pm 3.4$ defghi & 10 \\
\hline UCD1066So & B. dothidea & $17.2 \pm 5.8$ defghi & 8 \\
\hline UCD1965SB & Diplodia mutila & $16.6 \pm 4.1$ efghi & 10 \\
\hline UCD642So & Neofusicoccum parvum & $16.4 \pm 5$ efghi & 10 \\
\hline UCD2089Te & N. luteum & $15.2 \pm 0.9$ efghi & 9 \\
\hline UCD650So & N. parvum & $14.4 \pm 2.1$ efghi & 10 \\
\hline UCD1063So & B. dothidea & $13.8 \pm 1.6$ efghi & 8 \\
\hline UCD $1125 \mathrm{Na}$ & N. parvum & $11.8 \pm 4.7$ efghi & 9 \\
\hline UCD2073Te & Dothiorella viticola & $11.6 \pm 2.7$ efghi & 7 \\
\hline UCD1439SLO & Dothiorella iberica & $11.4 \pm 2.6 \mathrm{fghi}$ & 9 \\
\hline UCD244Ma & D. seriata & $11.2 \pm 2.6 \mathrm{fghi}$ & 10 \\
\hline UCD1410SLO & D. iberica & $10.4 \pm 1.8$ fghi & 9 \\
\hline UCD1953SB & D. mutila & $9.6 \pm 2.6$ ghij & 9 \\
\hline UCD2103Te & N. luteum & $8 \pm 1.1 \mathrm{hij}$ & 10 \\
\hline UCD288Ma & D. mutila & $7.6 \pm 1.4 \mathrm{hij}$ & 6 \\
\hline UCD1435SLO & D. viticola & $7.2 \pm 1.6 \mathrm{hij}$ & 6 \\
\hline UCD1642Yo & D. viticola & $6.6 \pm 1.4 \mathrm{ij}$ & 8 \\
\hline UCD1448SLO & D. iberica & $6.6 \pm 1.1 \mathrm{ij}$ & 4 \\
\hline Control & Control & $3.3 \pm 0.2 \mathrm{j}$ & 0 \\
\hline
\end{tabular}

${ }^{a}$ Means with the same letter are not significantly different at the 0.05 level. Mean values correspond to the sum of both upward and downward extent of vascular discoloration measured from the point of inoculation.

${ }^{b}$ Number of samples from which the fungus was reisolated out of 10 samples inoculated. parvum, and $N$. luteum isolates produced the largest lesions on both cultivars, and the extent of vascular streaking or discoloration was not significantly different from that of the well-documented canker pathogen E. lata (Table 4). Thus, the four Botryosphaeriaceae species were categorized as highly virulent on mature tissue. Based on the extent of the vascular discoloration and canker formation, $B$. dothidea on Red Globe, and B. dothidea, D. seriata, and D. iberica on Syrah were considered intermediately pathogenic on mature tissue (Table 4). Species that did not cause cankers or lesions that were not significantly different from the negative control included $D$. seriata, D. iberica, D. viticola, and D. mutila isolates on Red Globe, and D. viticola and D. mutila on Syrah (Table 4). However, these species were reisolated from observed lesions and were thus considered weakly virulent on mature tissue. Reisolation of the specific isolates, shown in Table 4, was accomplished. No Botryosphaeriaceae fungi were reisolated from the slightly discolored tissue from the controls.

Lath-house rooted grapevine inoculations. Mean length of vascular discolorations caused by the nine Botryosphaeriaceae isolates tested and control are shown in Table 5. Twelve months after inoculation, trunks had developed dark, rotting lesions and black wood streaking starting downward and upward from the point of inoculation. All nine Botryosphaeriaceae isolates tested were considered pathogenic and produced significantly longer lesions than the control $(7.3 \mathrm{~mm})$ (Table 5). However, lesion lengths varied among the isolates used in this study. The $L$. theobromae isolate caused the average largest lesion size $(92.1 \mathrm{~mm})$ (Table 5). The N. luteum, $N$. parvum, and $N$. australe isolates used in this assay were also highly virulent and caused lesions significantly longer than the rest of species shown in Table 5. Vascular discoloration caused by $D$. mutila, B. dothidea, D. iberica, D. viticola, and D. seriata did not differ significantly among each other and ranged from 19.8 to $24.1 \mathrm{~mm}$

Table 4. Mean lesion length caused by Botryosphaeriaceae species from California on cordons of cvs. Red Globe and Syrah

\begin{tabular}{|c|c|c|c|c|c|}
\hline \multirow[b]{2}{*}{ Isolate } & \multirow[b]{2}{*}{ Species } & \multicolumn{2}{|c|}{ Red Globe } & \multicolumn{2}{|c|}{ Syrah } \\
\hline & & $\begin{array}{l}\text { Mean lesion length } \\
\quad(\mathrm{mm}) \pm \mathrm{SE}^{\mathrm{a}}\end{array}$ & Reisolation $^{\mathrm{b}}$ & $\begin{array}{l}\text { Mean lesion length } \\
\quad(\mathrm{mm}) \pm \mathrm{SE}^{\mathrm{a}}\end{array}$ & Reisolation $^{\mathrm{b}}$ \\
\hline UCD1814Md & Lasiodiplodia theobromae & $80.2 \pm 5.6 \mathrm{a}$ & 10 & $80.4 \pm 6.7 \mathrm{a}$ & 10 \\
\hline UCD1314So & Neofusicoccum australe & $77.2 \pm 8.7 \mathrm{ab}$ & 7 & $68.4 \pm 7.5 \mathrm{ab}$ & 8 \\
\hline UCD642So & Neofusicoccum parvum & $75.1 \pm 9.7 \mathrm{ab}$ & 10 & $63.8 \pm 5.2 \mathrm{ab}$ & 10 \\
\hline UCD2118Te & Neofusicoccum luteum & $74.9 \pm 6.5 \mathrm{ab}$ & 8 & $72.5 \pm 4.3 \mathrm{a}$ & 10 \\
\hline DHB100 & Eutypa lata & $70.8 \pm 8 \mathrm{ab}$ & 8 & $60.1 \pm 3.2 \mathrm{ab}$ & 7 \\
\hline UCD1181Me & Botryosphaeria dothidea & $47.8 \pm 4.5 \mathrm{bc}$ & 7 & $42.6 \pm 5.9 \mathrm{~cd}$ & 6 \\
\hline UCD352Mo & Diplodia seriata & $40.2 \pm 5.9 \mathrm{~cd}$ & 7 & $35.9 \pm 3.6 \mathrm{de}$ & 8 \\
\hline UCD1448SLO & Dothiorella iberica & $35.8 \pm 8.8 \mathrm{~cd}$ & 6 & $32.8 \pm 2.5 \mathrm{de}$ & 7 \\
\hline UCD1642Yo & Dothiorella viticola & $34.2 \pm 8.1 \mathrm{~d}$ & 5 & $29.2 \pm 3.1 \mathrm{def}$ & 6 \\
\hline UCD1953SB & Diplodia mutila & $33.1 \pm 2.5 \mathrm{~d}$ & 6 & $30.3 \pm 5.8$ ef & 7 \\
\hline Control & Control & $26 \pm 1.4 \mathrm{~d}$ & 0 & $21.3 \pm 1.2 \mathrm{f}$ & 0 \\
\hline
\end{tabular}

${ }^{a}$ Means with the same letter are not significantly different at the 0.05 level. Mean values correspond to the sum of both upward and downward extent of vascular discoloration measured from the point of inoculation.

${ }^{b}$ Number of samples from which the fungus was reisolated out of 10 samples inoculated. 
(Table 5). Reisolation of the specific species is shown in Table 5. No Botryosphaeriaceae fungi were reisolated from the slightly discolored tissue from the controls.

Ranking analyses. Virulence of the nine Botryosphaeriaceae species across all pathogenicity assays was evaluated. According to Kruskal-Wallis test, $L$. theobromae was ranked as the most virulent species among all Botryosphaeriaceae species tested from California $\left(X^{2}=51.09\right.$, $P<0.0001$ ) (Table 6). N. luteum, N. parvum, and $N$. australe were ranked as the second, third, and fourth most virulent species, respectively (Table 2). Based on the overall lesion length, all four species were categorized as highly virulent. $B$. dothidea was considered intermediately virulent based on length of vascular discoloration among all species. D. mutila, $D$. seriata, $D$. iberica, and $D$. viticola were all categorized as weakly virulent (Table 6). $D$. iberica and D. viticola were considered the least virulent species among all Botryosphaeriaceae species tested in this study based on both discoloration length and reisolation percentage.

\section{DISCUSSION}

Perennial cankers and consequent to occur in California vineyards and have grapevine dieback have long been known

been thought to be associated with E. lata. Even though Leavitt first reported $L$. theobromae (Basionyn: Botryodiplodia theobromae Pat.) as the causal organism of bot canker disease in California in the late 1980s (11), it was not until recently that members of the family Botryosphaeriaceae and not E. lata were shown to be the main fungi isolated from grapevine cankers in the state $(29,33)$. This overlooked association between Botryosphaeriaceae species and grapevine dieback in California may correspond to the possibility that E. lata was considered throughout many years to be the only canker pathogen of grapevines. Furthermore, the inability to distinguish cankers caused by both $E$. lata and Botryosphaeriaceae species in the field as well as the lack of characteristic foliar symptoms associated with bot canker could contribute to the failure to identify these species as grapevine pathogens in California. However, the present study has shown clear evidences that all nine Botryosphaeriaceae species associated with grapevine cankers in California are pathogenic and capable of causing cankers, vascular discolorations, and dieback individually when inoculated into grapevines.

This study has shown L. theobromae to be the most virulent among all Botryosphaeriaceae species tested. Although $L$.

Table 5. Mean lesion length caused by Botryosphaeriaceae species from California on 2-years-old grapevine cv. Thompson Seedless

\begin{tabular}{llcc}
\hline Isolate & Species & $\begin{array}{c}\text { Mean lesion length } \\
(\mathbf{m m}) \pm \mathbf{S E}^{\mathbf{a}}\end{array}$ & Reisolation $^{\mathbf{b}}$ \\
\hline UCD220Co & Lasiodiplodia theobromae & $92.1 \pm 7.3 \mathrm{a}$ & 10 \\
UCD2098Te & Neofusicoccum luteum & $71.8 \pm 9.3 \mathrm{~b}$ & 10 \\
UCD646So & Neofusicoccum parvum & $49.7 \pm 6.9 \mathrm{bc}$ & 8 \\
UCD1314So & Neofusicoccum australe & $40.2 \pm 9.2 \mathrm{c}$ & 10 \\
UCD288Ma & Diplodia mutila & $25.3 \pm 3.7 \mathrm{~d}$ & 10 \\
UCD1066So & Botryosphaeria dothidea & $23.2 \pm 1.9 \mathrm{~d}$ & 9 \\
UCD1448SLO & Dothiorella iberica & $21.2 \pm 2.7 \mathrm{~d}$ & 7 \\
UCD2073Te & Dothiorella viticola & $19.9 \pm 2.1 \mathrm{~d}$ & 6 \\
UCD352Mo & Diplodia seriata & $19.8 \pm 2.3 \mathrm{~d}$ & 6 \\
Control & Control & $7.3 \pm 1.2 \mathrm{e}$ & 0 \\
\hline
\end{tabular}

${ }^{a}$ Means with the same letter are not significantly different at the 0.05 level. Mean values correspond to the sum of both upward and downward extent of vascular discoloration measured from the point of inoculation.

${ }^{\mathrm{b}}$ Number of samples from which the fungus was reisolated out of 10 samples inoculated.

Table 6. Virulence ranking of the nine Botryosphaeriaceae species from California on grapevines from most virulent (10) to least virulent (1)

\begin{tabular}{lcc}
\hline Botryosphaeriaceae species & Rank $^{\mathbf{a}}$ & Std. error \\
\hline Lasiodiplodia theobromae & 9.67 & 0.08 \\
Neofusicoccum luteum & 8.17 & 0.18 \\
Neofusicoccum parvum & 7.83 & 0.30 \\
Neofusicoccum australe & 7.67 & 0.13 \\
Botryosphaeria dothidea & 6.17 & 0.15 \\
Diplodia mutila & 4.33 & 0.19 \\
Diplodia seriata & 4.17 & 0.30 \\
Dothiorella iberica & 3.50 & 0.08 \\
Dothiorella viticola & 2.50 & 0.13 \\
Control & 1.00 & 0.00
\end{tabular}

a Virulence rank for each Botryosphaeriaceae species represents the average rank of each isolate across all six pathogenicity experiments (Syrah and Red Globe cordon inoculations were treated as separate trials) based on a Kruskal-Wallis test. Isolate ranks within each trial was determined from most virulent (rank 10) to least virulent (rank 2) including control (rank 1) based on length of discoloration they caused. theobromae has been consistently shown to be pathogenic on grapes by other authors $(1,11,28,31,34)$, variability in virulence has been observed in different grapegrowing regions. For instance, L. theobromae isolates from Western Australia (28), Mexico (31), and Spain (1) were shown to be highly virulent and caused the same type of vascular lesions as those reported in the present study. On the contrary, pathogenicity studies conducted in South Africa showed lesions caused by $L$. theobromae to differ little from the noninoculated controls (34). These differences could be due to variability in isolate virulence, type of inoculated tissue, shorter incubation periods, type of inoculum used, age of the host, and/or differences in cultivar susceptibility, among other possible factors. Virulence of $L$. theobromae isolates from California did not vary depending on type of inoculated tissue, cultivar, or with type of inoculum. L. theobromae has been reported to be more prevalent in grape-growing regions characterized by high temperatures and very low precipitation $(28,31)$. Our study showed $L$. theobromae isolates from Riverside County (Coachella Valley), an important grapegrowing area located in a desert area of Southern California, to be the most virulent among all isolates tested. Whether origins of isolates as well as environmental factors play a direct role in the virulence of L. theobromae remains unclear. Therefore, additional investigations considering the use of a broad number of $L$. theobromae isolates from different geographical regions in a multi-varietal pathogenicity study under different environmental conditions would be required to further clarify these hypotheses.

In this study, $N$. luteum, $N$. parvum, and $N$. australe followed $L$. theobromae in level of virulence and capability to produce cankers on grapes in California. Although $N$. luteum and $N$. parvum were first reported to be associated with declining grapevines in Portugal in 2002 (19), it was not until recently that their pathogenicity was first assessed on grapevines in South Africa (34). N. parvum isolates used in South Africa were considered highly virulent, and the only $N$. luteum isolate used in that study did not cause lesions any larger than the natural dieback associated with the control, and thus it was considered weakly pathogenic (34). The present study has shown N. luteum and N. parvum as two of the most virulent Botryosphaeriaceae species in California and confirms both species as important pathogens of grapes in the state. These results add to recent reports of pathogenicity of $N$. luteum in Eastern Australia (25) and N. parvum in Spain (14), where these species were shown to be the most virulent on grapes. Additionally, the present study also showed the association between $N$. parvum and dark wood streaking symptoms from 
which the fungus was commonly isolated in California and in seven other states (32). $N$. australe is mainly found in native and introduced plants in the Southern Hemisphere and is thought to be native to Australia (27). This species was primarily found associated with grapevine decline in South Africa (34) and Western Australia (28), where it was shown to be the most virulent Botryosphaeriaceae species. To date, California is the only grape-growing region from which $N$. australe has been found associated with grapevine dieback in the Northern Hemisphere (33). The present study also has confirmed the high level of virulence of $N$. australe on grapevines in California. Contrary to what has been observed with $N$. parvum in the United States, N. australe and $N$. luteum have a very narrow geographical distribution, and their occurrence is restricted to some vineyards in Northern and Southern California, respectively $(32,33)$. However, in view of their high level of virulence on grapes, further investigations are warranted to study its occurrence in other grapegrowing regions as well as in other hosts.

Overall, B. dothidea isolates from California caused less tissue discoloration than L. theobromae, $N$. parvum, $N$. luteum, and $N$. australe, but discoloration was still significantly longer than for $D$. seriata, $D$. mutila, D. iberica, and D. viticola, and thus $B$. dothidea was categorized as intermediately virulent in the present study. $B$. dothidea is confirmed to be responsible for excoriose in Portugal (18), and is associated with Macrophoma rot in the southeastern United States (16). Pathogenicity of $B$. dothidea on grapevines in California confirms its capability of causing cankers and agrees with previous reports from France (9) and Chile (10) in regards to its pathogenicity on grapes. In California, $B$. dothidea has been reported from over 90 native and introduced plant species including 30 different plant families $(4,15)$. Therefore, and in view of the important role that $B$. dothidea plays in grapevine health in California, further studies are needed to determine if its isolates from different hosts could act as potential sources of inoculum for grapevines and vice versa.

D. mutila, D. seriata, D. iberica, and D. viticola isolates from California caused small lesions, which occasionally were not different than the noninoculated controls, and thus were considered weakly pathogenic. D. mutila was first associated with grapevines as the cause of black dead arm in Hungary (12). However, little information is available in the literature regarding its pathogenicity on grapes. The current study has shown $D$. mutila isolates from California to be weakly pathogenic. The same conclusion was obtained from studies conducted in Portugal (18) and Australia (28). On the contrary, D. mutila was shown to be highly virulent in South Af- rica (34), reinforcing the previous idea that different factors might be involved in virulence variability in species of Botryosphaeriaceae. A recent study has shown $D$. mutila to be capable of infecting young grapevines through roots and causing dieback (35). In California, as well as other states surveyed, D. mutila was only isolated from cankers from spurs and cordons showing dieback symptoms $(32,33)$. However, only aerial parts of the plants were surveyed.

$D$. seriata has been shown to be a homogenous, cosmopolitan, and plurivorous species (21,22). Although D. seriata has been reported from grapevines in most continents, its pathogenicity on grapes has largely remained unclear (19). The lack of fulfillment of Koch's postulates from many studies associating $D$. seriata with grapevine decline symptoms $(3,23,24,30)$ and discrepancies regarding its virulence from studies where pathogenicity tests were conducted $(5,18,25,28,31,34)$ have added confusion in regards to its pathogenicity on grapevines during the past years. This study represents the first attempt to fully characterize the pathogenicity of $D$. seriata on grapes, and although the overall results showed this species to be a weak pathogen, there was a high level of variability among isolates. For instance, $D$. seriata was more virulent than $N$. parvum and $N$. luteum when inoculated in green tissue. Why green tissue is more susceptible to $D$. seriata isolates from California is unknown, and further investigations under field conditions are needed to determine the importance that this species may have in infection of vegetative growth. D. seriata has been commonly associated with black dead arm disease of grapes, which is characterized by light-brown discoloration of the wood and red patches at the margin of leaves and large chlorotic areas and deterioration between the veins $(2,9,12)$. Despite the fact that black dead arm vascular symptoms have been reproduced in this and previous studies $(2,9,31)$, the association between $D$. seriata and foliar symptoms of the disease has not been demonstrated. Therefore, whether black dead arm foliar symptoms are caused by $D$. seriata alone or by a complex of organisms still needs to be determined.

D. iberica and D. viticola have been recently described as new species in the Botryosphaeriaceae family $(13,20)$. Whereas both species have been isolated from grapevine cankers in California (29), only $D$. viticola has been found associated with grapevines elsewhere $(13,34)$. Based on results of this study, D. iberica and $D$. viticola isolates from California were the least virulent among all species tested, but still capable of causing vascular discoloration. D. viticola was found mainly on pruning debris and not associated with any decline symptom in Spain, and thus it was thought to act as a saprophyte (13). How- ever, this study has shown the capability of this species to colonize grapevine tissue to some extent, revealing the pathogenic role it has on grapevines in California.

Botryosphaeriaceae species have been shown to be isolated from grapevine dieback symptoms directly associated with pruning wounds and/or natural openings of the plant. Therefore, these fungi have been thought to infect grapes primarily through wounds $(25,28)$. This notion is true in California, where Botryosphaeriaceae species were isolated from cankers primarily developing from pruning wounds (33). Moreover, inoculations of fresh pruning wounds by spore suspensions of nine different Botryosphaeriaceae species in this study clearly showed that pruning wounds are susceptible to invasion by these pathogens. However, little information is available regarding the epidemiology of Botryosphaeriaceae infecting grapes. Further investigations to determine the environmental conditions that cause spore release and thus establish high-risk infection periods throughout the grapevine growing season in California are needed. This study also showed the capability of Botryosphaeriaceae species to infect and cause lesions on green tissue of the new vegetative growth. However, the implications that these results could have in the epidemiology of the disease are unknown at this time.

\section{ACKNOWLEDGMENTS}

This work was funded by grants from the American Vineyard Foundation and the Viticulture Consortium West. The authors acknowledge Casa Cristal Nursery (Delano, CA) for providing plant material to conduct both the greenhouse and lathhouse pathogenicity studies. We thank Dr. G. M. Leavitt (UCCE, Madera) for his valuable assistance in accomplishing the pathogenicity tests conducted at the University of California, Kearney Agricultural Center in Parlier.

\section{LITERATURE CITED}

1. Aroca, A., Raposo, R., Gramaje, D., Armengol, J., Martos, S., and Luque, J. 2008. First report of Lasiodiplodia theobromae associated with decline of grapevine rootstock mother plants in Spain. Plant Dis. 92:832.

2. Auger, J., Esterio, M., Ricke, G., and Pérez, I. 2004. Black dead arm and basal canker of Vitis vinifera cv. Red Globe caused by Botryosphaeria obtusa in Chile. Plant Dis. 88:1286.

3. Bonfiglioli, R., and McGregor, S. 2006. The Botryosphaeria conundrum; a New Zealand perspective. Aust. N.Z. Grapegrower Winemaker. Sept.:49-53.

4. Brooks, F. E., and Ferrin, D. M. 1994. Branch dieback of southern California chaparral vegetation caused by Botryosphaeria dothidea. Phytopathology 84:78-83.

5. Castillo-Pando, M., Somers, A., Green, C. D., Priest, M., and Sriskanthades, M. 2001. Fungi associated with dieback of Semillon grapevines in the Hunter Valley of New South Wales. Aust. Plant Pathol. 30:59-63.

6. Crous, P. W., Slippers, B., Wingfield, M. J., Rheeder, J., Marasas, W. F. O., Phillips, A. J. L., Alves, A., Burgess, T., Barber, P., and Groenewald, J. Z. 2006. Phylogenetic lineages in the Botryosphaeriaceae. Stud. Mycol. 55:235253.

7. Denman, S., Crous, P. W., Taylor, J. E., Kang, 
J.-C., Pascoe, I., and Wingfield, M. J. 2000. An overview of the taxonomic history of Botryosphaeria, and a re-evaluation of its anamorphs based on morphology and ITS rDNA phylogeny. Stud. Mycol. 45:129-140.

8. Hewitt, R. W. B. 1988. Diplodia cane dieback and bunch rot. Pages 25-26 in: Compendium of Grape Diseases. American Phytopathological Society, St. Paul, MN.

9. Larignon, P., Fulchic, R., Cere, L., and Dubos, B. 2001. Observations of Black dead arm in French vineyards. Phytophathol. Mediterr. 40:336-342.

10. Latorre, B. A., Besoaín, X., and Flores, V. 1986. Botryosphaeria canker of table grapes. Phytopathology 76:1112.

11. Leavitt, G. M. 1990. The occurrence, distribution, effects and control of Botryodipodia theobromae on Vitis vinifera in California, Arizona and northern Mexico. Ph.D. diss. University of California, Riverside.

12. Lehoczky, J. 1988. Black dead arm. Page 35 in: Compendium of Grape Diseases. American Phytopathological Society, St. Paul, MN.

13. Luque, J., Martos, S., and Phillips, A. J. L. 2005. Botryosphaeria viticola sp. nov. on grapevines: A new species with a Dothiorella anamorph. Mycologia 97:1111-1121.

14. Luque, J., Martos, S., Torres, E., and Garcia, F. 2007. Susceptibility of some grapevine varieties and rootstocks commonly used in Spain to decline-associated fungi. Phytopathol. Mediterr. 46:118-119.

15. Michailides, T. J., Morgan, D. P., and Ma, Z. 2003. New findings on band canker of almond caused by Botryosphaeria dothidea. Univ. Calif. Plant Prot. Quart. 13:1-6.

16. Milholland, R. D. 1988. Macrophoma rot. Page 24 in: Compendium of Grape Diseases. American Phytopathological Society, St. Paul, $\mathrm{MN}$.

17. Moller, W. J., and Kasimatis, A. N. 1978.
Dieback of grapevines caused by Eutypa armeniacae. Plant Dis. 62:254-258.

18. Phillips, A. J. L. 1998. Botryosphaeria dothidea and other fungi associated with excoriose and dieback of grapevines in Portugal. J. Phytophatol. 146:327-332.

19. Phillips, A. J. L. 2002. Botryosphaeria species associated with diseases of grapevines in Portugal. Phytopathol. Mediterr. 41:3-18.

20. Phillips, A. J. L., Alves, A., Correia, A., and Luque, J. 2005. Two new species of Botryosphaeria with brown, 1-septate ascospores and Dothiorella anamorphs. Mycologia 97:513529.

21. Phillips, A. J. L., Crous, P. W., and Alves, A. 2007. Diplodia seriata, the anamorph of Botryosphaeria obtusa. Fungal Div. 25:141-155.

22. Punitthalingam, E., and Waller, J. M. 1976. Botryosphaeria obtusa. Description of Pathogenic Fungi and Bacteria 394. Commonwealth Mycological Institute, Kew, Surrey, England.

23. Radman, L., and Nadazdin, V. 1981. A contribution to the study of two Sphaeropsis species parasites of the bark of grapevine in Herzegovina, Yugoslavia. Phytopathol. Mediterr. 20:83-84.

24. Rovesti, L., and Montermini, A. 1987. A grapevine decline caused by Spaheropsis malorum widespread in the province of Reggio-Emilia. Inf. Fitopatol. 37:1-59.

25. Savocchia, S., Steel, C. C., Stodart, B. J., and Somers, A. 2007. Pathogenicity of Botryosphaeria species isolated from declining grapevines in sub tropical regions of Eastern Australia. Vitis 46:27-32.

26. Siebert, J. B. 2001. Eutypa: The economic toll on vineyards. Wines Vines April:50-56.

27. Slippers, B., Fourie, G., Crous, P. W., Couthino, A. T., Wingfield, B. D., and Wingfield, J. M. 2004. Multiple gene sequences delimit Botryosphaeria australis sp. nov. from $B$. lutea. Mycologia 96:1030-1041.
28. Taylor, A., Hardy, G. E. St. J., Wood, P., and Burgess, T. 2005. Identification and pathogenicity of Botryosphaeria species associated with grapevine decline in Western Australia. Aust. Plant Pathol. 34:187-195.

29. Úrbez-Torres, J. R., Gubler, W. D., and Luque, J. 2007. First report of Botryosphaeria iberica and $B$. viticola associated with grapevine decline in California. Plant Dis. 91:772.

30. Úrbez-Torres, J. R., Gubler, W. D., Peláez, H., Santiago, Y., Martín, C., and Moreno, C. 2006. Occurrence of Botryosphaeria obtusa, B. dothidea and $B$. parva associated with grapevine trunk diseases in Castilla y León region, Spain. Plant Dis. 90:835.

31. Úrbez-Torres, J. R., Leavitt, G. M., Guerrero, J. C., Guevara, J., and Gubler, W. D. 2008 Identification and pathogenicity of Lasiodiplodia theobromae and Diplodia seriata, the causal agents of bot canker disease of grapevines in Mexico. Plant Dis. 92:519-529.

32. Úrbez-Torres, J. R., Leavitt, G. M., Guerrero, J. C., Guevara, J., Striegler, K., Allen, A., and Gubler, W. D. 2007. Identification of fungal pathogens associated with grapevine cankers in the main grape-growing areas of the United States and Mexico. Phytopathol. Mediterr. 46:109-110.

33. Úrbez-Torres, J. R., Leavitt, G. M., Voegel, T. M., and Gubler, W. D. 2006. Identification and distribution of Botryosphaeria spp. associated with grapevine cankers in California. Plant Dis. 90:1490-1503.

34. van Niekerk, J. M., Crous, P. W., Groenewald, J. Z., Fourie, P. H., and Halleen, F. 2004. DNA phylogeny, morphology and pathogenicity of Botryosphaeria species on grapevines. Mycologia 96:781-798

35. Whitelaw-Weckert, M. A., Sergeeva, V., and Priest, M. J. 2006 Botryosphaeria stevensii infection of Pinot Noir grapevines by soil-root transmission. Aust. Plant Pathol. 35:369-371. 